\title{
Leyes de Reforma y espiritualidad ignaciana en la obra del P. Antonio Labrador (1837-1915)*
}

\author{
Reform Laws and Ignatian spirituality in the \\ work of Fr. Antonio Labrador (1837-1915)
}

\section{Adriano DUQUE}

Dept. of Romance Languages \& Literatures

Villanova University

https://orcid.org/0000-0002-8255-5231

adriano.duque@villanova.edu

\begin{abstract}
Starting in 1873 , the Jesuits were re-admitted into the Church of México, and started a series of rural missions. Encouraged by initiatives like the «Apostolado de la cruz», the Jesuits made a concerted effort to establish a series of groups and initiatives destined to fight the liberalism of the Reform Laws. This paper studies the contribution of Antonio Labrador S. J., from when he joined the Rural Missions in 1885, until his return to Spain in 1910.
\end{abstract}

Keywords: Jesuits; missions; Mexico; Antonio Labrador.
Resumen: En 1873, coincidiendo con la reincorporación de los jesuitas a la vida eclesiástica en México, la Compañía de Jesús inició una campaña de misiones rurales. Instigado por iniciativas populares como el «Apostolado de la Cruz», la compañía de Jesús se esforzó por establecer una serie de agrupaciones y de iniciativas encaminadas a luchar contra el liberalismo de las leyes de Reforma. En el artículo se estudia la contribución del P. Antonio Labrador S. J., desde su incorporación en 1885 a las misiones rurales hasta su regreso a España en 1910.

Palabras clave: jesuitas; misiones; México; Antonio Labrador.

* Debo expresar mi agradecimiento a Francisco Crosas, Enrique Chacón y a Margarita Iriarte por sus sugerencias a la hora de escribir este artículo. Los errores que pueda haber en él son míos. 
La promulgación de las leyes de Reforma representa uno de los momentos clave de ruptura entre la Iglesia y el Estado mexicano. Bajo pretexto de promover la libertad de culto, la constitución mexicana de 1857 otorgó a los poderes federales expresa intervención en materia de culto religioso y convirtió lo que había sido un problema de conciencia en una cuestión de alcance político social. Si bien es verdad que los jesuitas habían apoyado la causa del patriotismo criollo, su regreso a México en 1873 se caracterizó por una oposición frontal a las leyes de reforma ${ }^{1}$. En su esfuerzo por buscar una forma de atraerse a los liberales, el presidente Sebastián Lerdo de Tejada (1823-1899) recrudeció la campaña contra los jesuitas ${ }^{2}$. Ante esta situación, los directores de la compañía de Jesús emprendieron una campaña de evangelización bajo pretexto de continuar la labor de los misioneros rurales, limitados eso sí por las directrices de la orden de no tomar partido en las cuestiones políticas de la época ${ }^{3}$. Así al menos se manifestaba el P. Anderledy, quien en 1889, ante la crisis integrista de la Compañía, aconsejaba «no mezclarse en la política partidista, tratar con todos los grupos, esforzarse en unir a los católicos, actuar de acuerdo con los obispos y dedicarse exclusivamente a los ministerios propios de la vocación religiosa» ${ }^{4}$.

Uno de los centros de propagación de las misiones rurales fue el colegio de San Juan Nepomucemo de Saltillo (Coahuila). Fundado en1878, el colegio fue regentado por los PP. Ignacio Velasco (1834-1891) y Alberto Cuscó Mir. Animado por el establecimiento de la congregación del Apostolado de la cruz, el P. Cuscó Mir se vio pronto enfrentado con las autoridades eclesiásticas, que veían con recelo las demostraciones espontáneas de devoción popular ${ }^{5}$. En un esfuerzo

1 Guillermo ZERMEÑo PADILLA, El retorno de los jesuitas a México en el siglo XIX: algunas paradojas, en El Colegio de México, 64/4 (2015), p. 1524.

2 Paola Chenillo AlazRaKi, Liberalismo a prueba. La expulsión de los extranjeros perniciosos en México durante la república restaurada (1867-1876), en Revista de Indias, 72/255 (2012), p. 385.

3 Cfr. Gerard Decorme, Historia de la Compañia de Jesús en la República mexicana, Ediciones Canisio, Chibuabua, 1959, vol. 3, p. 90.

4 Manuel RevUelta, Estabilidad y progreso de la Compañia durante la restauración alfonsina (18751931), en Los jesuitas en España y en el mundo hispánico, ed. Teófanes Egido, Marcial Pons, Madrid, 2004, p. 322.

5 Camile Foulard, Hacia los límites del cuerpo: Prácticas penitenciales de una mística católica en la Revolución Mexicana, en Trace, 72 (2017), pp. 9-33. La ortodoxia del P. Labrador le llevó a enfrentarse con el P. Cuscó Mir durante la cuaresma de 1986. Según explica José Gutiérrez Casillas, el P. Labrador escribió a sus superiores acusando al P. Mir de que en sus sermones tan sólo trataba de hacer que llorara la gente, que no daba bien los ejercicios «y que son sus devotuelas las que lo consideran mejor». La raíz del problema estaba en la defensa que el P. Cuscó Mir había hecho de la congregación del Apostolado de la Cruz. El P. Labrador, que era opuesto al apostolado, exigió al P. Cuscó Mir que se limitara a hacer las pláticas doctrinales. Quizás movido por el 
por replicar el éxito que el P. Armando Brissack (1836-1887) había tenido en colegio de los Jesuitas de Puebla, las autoridades religiosas decidieron ponerlo al mando del colegio de Saltillo con la instrucción explícita de que de que reforzara el cumplimiento de la observancia religiosa ${ }^{6}$.

En 1884, un año antes de tomar posesión de su cargo, el P. Brissack viajaba a Europa para reclutar voluntarios con los que poblar el colegio de Saltillo. Al pasar por España, el P. Brisack conoció a un jesuita andaluz, el P. Antonio Labrador, quien había adquirido cierta fama como predicador en la provincia de Burgos y quien enseguida se ofreció a acompañarlo a México. Para marzo de 1886, el P. Labrador ya había dado su primera misión en la iglesia de Parras (México) e iniciaba una carrera que lo llevaría a sufrir prisión en la cárcel de Granaditas entre los años de 1889 y 1890 bajo pretexto de que había contravenido las leyes de Reforma.

Nacido en Zufre (Huelva) el 25 de abril de 1837, el P. Labrador pasó sus primeros años de formación en Valverde de Leganés (Badajoz) en compañía de su hermano José (1811-1883), quien en 1863 sería designado como arcipreste de la iglesia de Santa María del Mercado en Alburquerque (Badajoz) ${ }^{7}$. Entre 1849 y 1853 Antonio Labrador asistió al Instituto provincial de Badajoz que en aquellos años estaba regentado por D. José Muntadas Andrade ${ }^{8}$. La dedicación

mismo sentimiento, en 1898 y a instancias del P. Labrador, su hermana Francisca construyó en la iglesia del pueblo de Zufre «un precioso altar dedicado a la Sagrada Imagen del Corazón de Jesús; cuya inauguración se efectuó el 20 de junio de 1898». El 23 de julio de 1903 se daba cuenta además de la donación de dos cuadros, uno del sagrado corazón de Jesús y otro de la Virgen de Guadalupe. Por la correspondencia entre el P. Antonio y su sobrina Rosario se sabe además que el P. Labrador dispuso que se fundara una cofradía dedicada a la Virgen de Guadalupe de cuyo mantenimiento se encargaron sus familiares. En este sentido se establece en el acta de donación que «desde entonces, todos los años se efectúa en esta parroquia una concurrida novena y función solemne, en su día, al Sagrado Corazón de Jesús, con comunión general». «Acta de donación», Archivo parroquial, Iglesia de Zufre, 1898. En dicho documento se incluye una nota de 1903, dando cuenta de la donación de los cuadros. Cfr. copia en AECJ, leg. 1471.

6 José Roberto Mendirichaga Dalzell, El colegio de San fuan Nepomuceno, 1878-1914: presencia de los fesuitas desde Saltillo, Tesis doctoral, Universidad Iberoamericana, México D. F., 2007, p. 136. En 1873 los PP. Gómez Cumplido, Provincial de Castilla y Andrés Artola Visitador de México, firmaron un convenio por el que la provincia de Castilla se comprometía a admitir cada año a tres escolares y un coadjutor, que serían destinados a México después de unos años de formación, y cuyos gastos correrían a cargo de la provincia mexicana. Cfr. Manuel REvUELTA, Las misiones de los jesuitas españoles en América y Filipinas durante el siglo XIX, en Miscelánea Comillas, 46/88-89 (1998), p. 344.

7 Parte oficial, vacantes en las diócesis en La esperanza, Periódico Monárquico, 15 de junio 1863.

8 Un año antes de que el P. Labrador entrara en el colegio, el boletín del ministerio de Comercio e Instrucción daba cuenta de la situación del instituto, diciendo que «el estado de este instituto es 
de D. José Muntadas al instituto de Badajoz es una constante en los numerosos informes de aquellos años y se basaba en un programa educativo cuyo propósito era «probar con la historia filosófica de las naciones que la Religión y la Moral son indispensables para el desarrollo de las facultades intelectuales, deduciendo de este principio la importancia de su estudio para el adelantamiento y legítimo progreso de la humanidad en todos los ramos que abraza el entendimiento del hombre»?

En 1853 Antonio Labrador pasó a la Universidad de Sevilla, donde se matriculó de cursos de Teología. Dos años más tarde, el 30 de octubre de 1857, escribía a su hermana Francisca y le comunicaba su inminente decisión de profesar en la Compañía

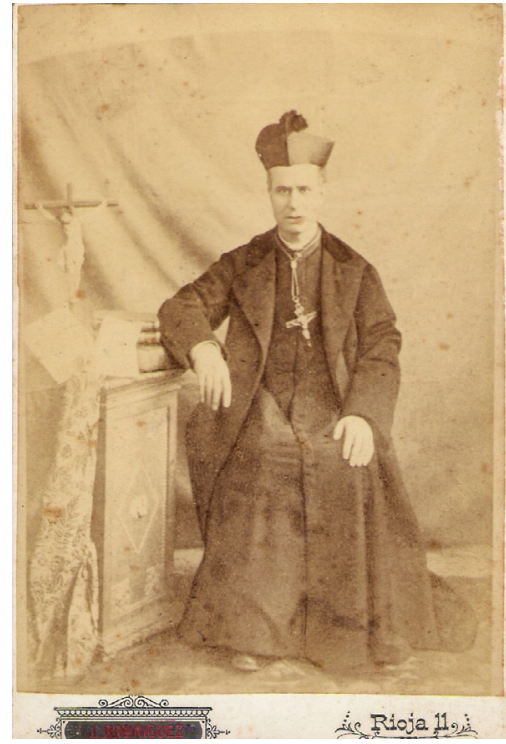

P. Antonio Labrador, S.J., Sevilla, c. 1880 (col. del autor). de Jesús, donde entraría el 12 de noviembre $^{10}$. Ocho años más tarde, el 15 de agosto de 1865 celebraba su primera misa como sacerdote en la iglesia de San Marcos de León, apadrinado por su hermano José.

El 13 de octubre de 1868, el gobierno provisional pronunció el decreto de supresión de la orden de los jesuitas. Según Manuel Revuelta, la supresión se produjo por conspirar contra los poderes constituidos ${ }^{11}$. Aun cuando las autoridades

deplorable: estrecho el local, mal dispuestas las aulas, sin poder tener alumnos internos, y satisfechas con mucho atraso las asignaciones de los catedráticos. En vano el director reclama el pago de la cuota mensual que debe pagar la provincia, con arreglo a su presupuesto; y la desaplicación e indocilidad de los alumnos ha hecho que diez de estos hayan perdido el curso». Boletín oficial del Ministerio de Comercio, Instrucción y Obras. Madrid, 1848. Cfr. José MunTADAS ANDRADE, Memoria que sobre el Instituto de Badajoz durante el curso de 1959 á 60, leyó en la solemne apertura del curso, el 16 de septiembre de 1860, el Sr. director del mismo Don fosé Muntada y Andrade, Imp.y Lib. de D. G. Orduña, Badajoz, 1859.

9 Discurso inaugural pronunciado en la apertura del curso de 1851-1852 del instituto de Badajoz, manuscrito, A.C.A.A, legajo 6868, cit. Felicidad SÁNCHEZ PASCUAL, El instituto de segunda enseñanza de Badajoz en el siglo XIX (1845-1900), Excma. Diputación, Badajoz, 1985, p. 166.

10 Carta a Francisca Labrador, 30 de octubre 1857, AECJ, leg. 1471.

11 Manuel Revuelta, La Compañía de Jesús en la España contemporánea: Supresión y reinstalación, vol. 3, Sal Terrae, Madrid, 1984, p. 407. 
de Burgos no adoptaron ninguna resolución en contra de las órdenes religiosas, los decretos del ministro de Fomento Ruiz Zorilla bastaron para reconocer la libertad de culto y debilitar la labor de la Iglesia ${ }^{12}$. Al contrario de lo que ocurriría con otros grupos, los jesuitas recibieron la prohibición de reunirse en comunidad, lo que contribuyó a su dispersión ${ }^{13}$. Ante esta situación, el P. Labrador se vio obligado a refugiarse en casa de su hermano en Alburquerque entre 1868 y 1871, ocupándose de la educación de «algunos niños» ${ }^{14}$. En 1871, el P. Labrador pasó a la residencia jesuítica de Palencia donde se juntó con el P. José Antonio Delgado que había sido expulsado del convento de Carrión y que llegaría a ser ecónomo de la iglesia catedral. ${ }^{15} \mathrm{El} \mathrm{P}$. Labrador por su parte fue nombrado director de la cofradía del Carmen, que estaba instalada en la antigua iglesia de la Compañía ${ }^{16}$. Fue allí mismo, en 1871, donde dio su primera homilía, coincidiendo con la predicación de la novena de Jesús Nazareno ${ }^{17}$.

A medida que se recuperaba de los efectos de la expulsión, la Compañía de Jesús buscó reanudar la campaña de misiones rurales. Para ello, se elaboró un plan metódico que concebía la misión como «una modalidad e instrumento de evangelización» itinerante cuyo propósito no era catequizar, sino también «enfervorizar y desterrar abusos y pecados». Apelando a su experiencia y conocimiento de la psicología popular, los misioneros utilizaron recursos efectistas y emplearon una oratoria simple, directa, que hablaba más al corazón que al

12 Entre otras disposiciones, Ruiz Zorrilla suprimió la asignatura de religión en los planes de estudios de los institutos y las facultades universitarias, además de las facultades de Teología en las universidades. Un segundo decreto fue el que determinó la incautación de las colecciones de ciencia, arte o literatura que estaban a cargo de las catedrales, cabildos, monasterios u órdenes militares, exceptuando las bibliotecas de los seminarios. Vicente CARCEL ORTI, Iglesia y revolución en España, EUNSA, Pamplona, 1979, pp. 147-150.

13 Antonio MOLINER PRADA, Algunos aspectos del anticlericalismo español en la revolución de 1868, en Investigaciones históricas. Época Moderna y contemporánea, 14 (1994), p. 145.

14 Manuel Revuelta, La Compañía de Jesús, vol. 1, p. 193.

15 Lesmes FRÍAS, La provincia de Castilla de la Compañia de fesús desde 1863 hasta 1914: reseña histórica, El Mensajero del Corazón de Jesús, Bilbao-Deusto, 1915, p. 53. En el tomo I se reproduce un grabado con las formas de la comunidad de Carrión, con ocasión de su disolución el 20 de octubre de 1868. El P. Labrador fue quien recogió las firmas. Manuel REvUELTA, La Compañia de Jesús, vol. 1, p. 139.

16 Manuel Revuelta, La Compañía de fesús, vol. 1, p. 646.

17 La Propaganda 3, 20. Las Cartas de Poyanne publicadas entre 1877 y 1878 contienen una extensa relación de las misiones llevadas a cabo por el P. Labrador entre 1871 y 1878 . El P. Labrador llevó a cabo misiones en Grijota (CP 7, 53); Baltanás, Cevico de la Torre, Vertavillo, Osorno (CP 9, 23-30); Tordehumos, Villabrágima, Castromonte, Mudarra, Montealegre, Río Tirón, Redecilla del Campo, Belorado, Pradoluengo, Santurde, Valgañón, Ezcaray, Santurdejo, Villerías (CP 9, 62-74). 
entendimiento. Dicho estilo contrastaba con el estilo culto de predicación entonces en su apogeo. Por lo general, los misioneros actuaban en parejas, por un itinerario previamente trazado y cuyas autoridades eran advertidas para que cooperasen con ellos ${ }^{18}$.

El P. Labrador ayudó a impulsar el nuevo estilo de evangelización ${ }^{19}$. Sin duda el testimonio más valioso sobre su predicación procede del P. Laureano Veres (1844-1922), quien conoció personalmente al P. Labrador y quien se encargó de redactar las cartas ejemplares escritas a su muerte. Cuenta así el P. Veres que estando una vez en León, el Sr. Obispo insistió en dar un sermón en la catedral. La voz del obispo era débil y apenas se le entendía. El Padre Labrador subió entonces al púlpito, se colocó detrás del prelado y fue repitiendo con voz estertórea todo lo que decía. El P. Antonio Repiso, que lo oyó predicar el 14 de agosto de 1893, atribuía a uno de sus sermones su decisión de profesar en la casa de los jesuitas:

Eran las misiones que daba el experimentado P. Labrador modelos, a lo que creo, en su género. Cánticos, procesiones, sermones de aparato, cuando convenían, oportunísimos; sólida y popular doctrina, que ensanchaba el ánimo y partía; sermones por completo inteligibles al pueblo y de interés y escogida alocución para los doctos, conmovedores siempre y respirando fuego de amor de Dios y abrasadoras ansias de la salvación de las almas; constante atención al confesionario y administración frecuente de la sagrada Eucaristía; conferencias al clero y a comunidades religiosas; catecismos, visitas de enfermos y de encarcelados, no hay medio alguno eficaz y recomendable que no se emplease entonces para la conversión de los pecadores y el mayor aprovechamiento de los justos ${ }^{20}$.

Dentro de la tradición homilética de la Compañía de Jesús, el sermón ponía mayor énfasis en las buenas obras que en la palabra. Así al menos se expresa Jerónimo Nadal cuando recomienda refutar el error de los herejes siempre que la ocasión lo exija, poniendo mayor énfasis en las obras de caridad y en el ejemplo

18 María Soledad GómeZ NAVARro, Con la palabra y los gestos. Las misiones populares como instrumento de cristianización y recristianización en la España Moderna, en Ámbitos, 19 (2008), pp. 11-23. Para una exposición sobre las misiones populares en la compañía de Jesús, v. Manuel REvUELTA, La Compañia de fesús en la España Contemporánea, vol. 3, Sal Terrae, Madrid, 1984, pp. 117-302.

19 Cfr. Manuel Revuelta, La Compañía de fesús, vol. 1, p. 316. El P. Labrador se refiere a sí mismo con frecuencia como misionero, sin duda aludiendo a su responsabilidad de llevar a cabo misiones esporádicas. Para una distinción entre el «missionarius discurrens» y el «missionarius» a secas, v. Manuel Revuelta, La Compañia de fesús, vol. 1, p. 132.

20 СЕРТ (1911-1923), vol. 5, p. 281. 
que en la confrontación o la controversia ${ }^{21}$. Fiel a esta escuela, el primer sermón palentino del P. Labrador (1871) tomaba como referencia una cita de la epístola de San Pedro y prevenía a los palentinos de que no cayeran en el error de los necios, engañados por su aparente seguridad: «Vos igitur fratres, præscientes custodite, ne insipientium errore traducti excidatis a propria firmitate» (2 Petr 3, 17). A partir de esta cita contra los herejes, el P. Labrador dirige su atención a la temeridad de aquellos que dan un sentido arbitrario a las Escrituras.

Haciendo causa común del liberalismo y la herejía, el sermón de Palencia tomaba partido por una visión católico-nacionalista del cristianismo en una época de marcada oposición a la Iglesia y en especial, al apostolado de los PP. jesuitas. Partiendo de la idea de justicia, el P. Labrador se hacía eco del «gran peligro en que se halla la fe verdadera en España» y denunciaba el «poco amor a las prácticas de la Religión Católica». Al mismo tiempo, buscaba en la figura de Santo Toribio un modelo para luchar contra la herejía: «Palencia fue testigo de su celo en aquella edad; Palencia está en la imprescindible necesidad de ser salvada ahora por su mismo celo». En su conclusión, el P. Labrador recomendaba «expeler la ignorancia, promover la humildad cristiana, corregir las costumbres y excitar la práctica de la religión $\gg^{22}$.

\section{PRIMERAS MISIONES EN MÉXICO}

Los primeros años del P. Labrador México coincidieron con un proceso de laicidad del estado que sin embargo no afectó de la misma panera a las clases populares $^{23}$. En un esfuerzo por atender las necesidades de las comunidades rurales, el P. Brisack encauzó la misión del colegio de Saltillo y emprendió una serie de misiones en compañía de los nuevos miembros. La orientación católica del colegio se tradujo en un currículo estricto que trataba de conciliar la responsabilidad moral con la responsabilidad civil. Para el año 1896, afirma Jean Pierre Bastian, el examen final del curso de filosofía del Colegio de Saltillo argumentaba «que la naturaleza del hombre reclamaba la autoridad civil y que por lo tanto eran falsos el contrato social de Rousseau y el sistema social de Hobbes. Se afirmaba también

21 John O'MaLley, Saints or Devils Incarnate? Studies in fesuit History, Brill, Leiden, 2013, p. 129.

22 Sermón de Santo Toribio, ¿16 abril 1871? AECJ, leg. 1471. Para una descripción de las misiones del P. Labrador en Castilla, v. Manuel RevuelTa, La Compañia de Jesús, vol. 1, p. 316.

23 Corina YTURBe, Las Leyes de Reforma: ¿Laicidad sin secularización?, en Isonomía, 22 (2010), pp. 6581 . 
que la autoridad civil o política no era obra del hombre sino que venía inmediatamente de Dios y que por lo tanto, no residía en el cuerpo de la nación como lo pretendían Rousseau y los racionalistas y que, en consecuencia, el parlamentarismo era un mecanismo intrínsecamente imperfecto» ${ }^{24}$.

Fundamentalmente, el currículum del colegio de San Juan de Saltillo seguía el catolicismo militante de la encíclica Rerum novarum (1891) y se caracterizó por una oposición férrea al liberalismo de autores como Carl Joseph Anton Mittermaier que defendían la independencia del poder judicial y la separación de poderes, como garantía de equilibrio entre seguridad y libertad ${ }^{25}$. La reedición en México en 1887 del libro del sacerdote catalán Félix Sardá y Salvany (18411916) El liberalismo es pecado (1884) marcó sin duda una oposición al pensamiento de Mittermaier y planteó la necesidad de regirse por catolicismo dogmático e inmutable ${ }^{26}$. Fiel reflejo de la contienda entre integristas y católicos moderados, El liberalismo es pecado planteaba el problema de la actitud de los católicos ante las constituciones y libertades modernas y proponía acomodar la religión a las necesidades y contingencias de la sociedad.

Basado en las encíclicas de Gregorio XVI Mirari vos (1832) y el Syllabus de Pío IX (1864), El liberalismo es pecado se expandió rápidamente entre las comunidades de jesuitas. No en vano, en las relación de cargos contra el P. Labrador en 1889, el juez de turno acusó al P. Labrador de haberle obsequiado un ejemplar del libro de Sardán ${ }^{27}$.

La llegada de los PP. Jesuitas afianzó por otra parte la labor del P. José Alzola (1879-1900), superior de la orden, y bajo cuyo mando prosperó la provincia jesuítica ${ }^{28}$. Con todo y con eso, la situación de las leyes de Reforma a finales de la época de 1880 seguía siendo preocupante. Si bien es verdad que el presidente Manuel González Flórez (1883-1993) había hecho la guerra en el bando conservador (1846-1861), la vuelta progresiva de los jesuitas durante el gobierno de Porfirio Díaz supuso un recrudecimiento de la hostilidad hacia la Compañía para

24 Jean Pierre BASTIAN, Protestantes, liberales y francmasones: Sociedades de ideas y modernidad en América Latina, siglo XIX, Fondo de Cultura Económica, México D. F., 1990, p. 144.

25 Félix Herzog, La crisis de los principios espirituales y sociales del proceso penal reformado, en Ius et Praxis, 15/1 (2009), pp. 375-386.

26 Elisa Cárdenas Ayala, El fin de una era: Pío IX y el Syllabus, en Historia Mexicana, 65/2 (2015), pp. 719-746.

27 V. Solange HiBBS-LissorguEs, El liberalismo es pecado. Estudio preliminar y edición, Pagès Editors, Lérida, 2009.

28 Esteban J. Palomera, La obra educativa de los jesuitas en Guadalajara, 1586-1986, Instituto de Ciencias, México D. F., 1997, p. 157. 
desacreditar aún más a los jesuitas ${ }^{29}$. El final de la administración del presidente Manuel González (1880-1884) y la muerte súbita de Sebastián Lerdo de Tejada en Nueva York en enero de 1889 dieron paso a la dictadura de Porfirio Díaz, quien en un esfuerzo por afianzar su poder entre las filas conservadoras fue concediendo salvoconductos a los jesuitas que habían sido desterrados ${ }^{30}$.

La predicación de las misiones rurales era vista con sospecha por las autoridades civiles y resultó en un número de arrestos bajo pretexto de defender las leyes de Reforma ${ }^{31}$.

Uno de los casos más notables fue el arresto del P. Alberto Cuscó y Mir (1872-1916) quien en 1878 había sido enviado al colegio de Saltillo para completar su magisterio. Su amistad con Concepción Cabrera de Armida le hizo ser un fiel defensor de la congregación del Apostolado de la Cruz, atrayéndose la enemistad tanto de las autoridades civiles como religiosas. En 1889, el P. Cuscó fue acusado de «haber retraído de la vida mundana y encaminado a la religión a una cuñada del gobernador Garza Galán (1886-1893)». Para evitar mayores disturbios, los superiores de la orden lo destinaron un tiempo al noviciado de $\mathrm{S}$. Simón, de donde pasó a España, donde permaneció hasta 1909². En este espíritu de cosas, un año más tarde, en 1890, el diputado liberal D. Juan A. Mateos (1831-1913) demandó a la cámara de diputados que se prohibiera la residencia en México a cualquier sacerdote extranjero, haciendo que el Padre José Soler, rector del seminario conciliar de México, viviera algún tiempo en casas particulares ${ }^{33}$.

Sin duda alguna, influencia de Concepción Cabrera de Armida se hizo sentir grandemente y se manifestó en una serie de disturbios que afectaron el desarrollo normal de las misiones y que ponían en evidencia las diferencias sociales dentro de las Iglesias.

Uno de los acontecimientos más sonados tuvo lugar durante la misión de Guanajuato, durante la cual el P. Labrador hubo de mezclarse entre los feligreses.

29 Guillermo ZERMEÑo PADILLA, El retorno, p. 1466.

30 Esteban J. PALOMERA, La obra educativa, p. 26.

31 La primera misión del P. Antonio en México fue en Parras (Coahuila) a donde acudió en compañía del P. Brissack y donde volverían a predicar en 1886. Desde allí emprendió una labor evangelizadora, e inició un nuevo campo de apostolado junto con el P. Alberto Cuscó (1852-1916) y Manuel Piñán (1918) en las «misiones rurales», tomando como centro de operaciones el Beaterio de Jalapa y el Santuario de la Virgen de los Ángeles en México, donde llegó a celebrar dos novenas en 1895 y 1896. José GUTIÉRREZ CASILlaS, Fesuitas en México durante el siglo XIX, Porrúa, México D. F., 1972, p. 245.

32 José Roberto MENDiRichaga Dalzell, El colegio, p. 170.

33 José Gutiérrez Casillas, fesuitas en México, p. 246. 
La descripción que hace el P. Veres de aquella predicación da idea de la forma en la que se desarrollaban las misiones:

Sucedió cuando estábamos en la misión de Guanajuato, que, para perjudicar e impedir a las señoras la asistencia a los sermones, algunas malas mujeres, ostentando mucha piedad, introducíanse entre ellas en la iglesia, y con mucho disimulo cortábanles por algunas partes los vestidos mientras que con santa avidez oían aquéllas la divina palabra. Supo esto el P. Labrador, y santamente indignado se propuso vigilar por sí mismo por si lograba sorprender en aquel delito a las criminales; pero hízolo una noche inmediatamente después de haber predicado, sudando todavía y abiertas de par en par las puertas de la iglesia, y tan piadoso exceso atrajo sobre él una enfermedad que puso su vida en peligro ${ }^{34}$.

En otra ocasión, los indios del pueblo de San Juan invitaron al Padre Antonio y al Padre Ipiña a que fueran al pueblo de San Juan y cuando llegaron los recibieron con una banda de música, repique de campanas y gran estruendo de cámaras y cohetes. Las calles estaban adornadas de flores y las puertas y ventanas de las casas estaban adornadas con cortinas. Al llegar a la iglesia, los incensaron con pebeteros y los indios principales cantaron algunas canciones. A continuación, el Padre Labrador comenzó a predicar. En las paredes de la iglesia había grandes cuadros que representaban a los apóstoles, y el Padre aprovechó para exaltar las acciones de aquellos varones. En aquel momento una anciana le interrumpió y le dijo:

-Ahí los puso mi abuelo, padrecito.

-Pues tu abuelo se conoce que era hombre que lo entendía, cristiano viejo, desinteresado y amante de la gloria de Dios. Imitadle todos en su celo por adornar la casa de Dios, y sobre todo en su piedad. Conservad como fieles custodios esos cuadros, que son de Dios por ese motivo, y todo cuantos vuestros padres han dado para el culto divino ${ }^{35}$.

\section{EL SERMÓN DE PUEBLA (1888)}

El 23 de mayo de 1888, el gobierno de Porfirio Díaz aprobaba la ley de enseñanza obligatoria, por la que se indicaba la forma de subvencionar las escuelas municipales y donde establecía que la instrucción primaria dada por el Estado

\footnotetext{
34 CEPT (1911-1923), Madrid, 1914, vol. 5, pp. 281-283.

35 CEPT (1911-1923), Madrid, 1914, vol. 5, pp. 186 y 281.
} 
sería gratuita, al mismo tiempo que prohibía que la impartieran ministros de cualquier culto religioso. Las materias consideradas como básicas en esta Ley incluían la: «instrucción moral y cívica, la lengua nacional, la lectura y escritura, las nociones de cálculo aritmético y geometría, los elementos de ciencias fundamentales de observación y experimentación, datos elementales de geografía y nociones de historia natural, dibujo, canto coral, manejo de los útiles de los oficios mecánicos, ejercicios gimnásticos, ejercicios militares para niños y labores manuales para niñas» ${ }^{36}$.

En aquel mismo año, el P. Labrador predicaba en las ciudades de Tlacotalpan, Alvarado y otras del Estado de Veracruz, acompañando al obispo en la visita de su diócesis. Preocupado sin duda por la marcha de los acontecimientos de la nación, el P. Labrador usó el púlpito de Puebla para pronunciar un sermón que marcaría un hito en su lucha contra el liberalismo de aquellos años. Para iniciar su causa, el P. Labrador echó mano de un pasaje de la Biblia (Josué 10:5) que Fr. Diego Miguel Bringas ya había utilizado en 1813 para referirse al orden de la justicia ${ }^{37}$. En dicho pasaje, el P. Labrador recordó cómo los cinco reyes de los amorreos se juntaron para luchar contra Gabaón, y cómo Dios ayudó a Gabaón frente a sus enemigos: «Dixitque Dominus ad Josue: Hodie abstuli opprobrium Ægypti a vobis. Vocatumque est nomen loci illius Galgala, usque in præsentem diem» $(10: 5)$.

Reciente aún la memoria de las riadas que tuvieron lugar en Puebla el 16 de febrero de 1888, el P. Labrador no dudó en evocar en aludir a los copiosos granizos «con los que huyeron derrotados». El mensaje era claro: «Josué combate, Dios le auxilia: vence consiguiendo se alargue el día alumbrando el sol cuando fue necesario para acabar con los enemigos; lo mismo tenemos que hacer nosotros, valiéndonos del poderoso auxilio del Señor, disipando la ignorancia y otros medios de que se vale en nuestros días el demonio para destruir la religión y corromper la sociedad (...) Tengamos fe. Oremos y trabajemos» ${ }^{38}$.

La victoria de Josué aparece ya como un tema en obras como el Liberalismo es pecado y residía en el convencimiento de la superioridad de la oración sobre «la pluma de los controversistas y la espada de sus capitanes». Al igual que Sardá, el P. Labrador concebía la oración como el arma principal para sobreponerse

36 Ernesto Meneses, Tendencias educativas oficiales en México, 1821-1911, Centro de Estudios Educativos y Universidad Iberoamericana, México, 1998, p. 429.

37 J. E. HERnÁNDEZ y DÁvalos, Colección de documentos para la historia de la Guerra de Independencia de México, vol. 4, J. M. Sandoval, México D. F., 1878, p. 541.

38 Antonio Labrador, Sermón 1, La Puebla de los Ángeles, 1888, p. 1, AECJ, leg. 1471. 
a los enemigos. En el mismo sentido se manifiesta pues Sardá cuando escribe: «Con argumentos y réplicas se obliga tal vez a enmudecer al adversario, Y no es poco esto en algunas ocasiones. Pero con esto solo no se alcanza muchas veces su conversión. Para esto suelen valer tanto o más las fervorosas oraciones que los más bien hilados raciocinios» ${ }^{39}$.

\section{ENCUENTRO CON EL PRESIDENTE MANUEL GONZÁLEZ FLÓREZ}

Uno de los episodios más conocidos de la vida del P. Labrador en México ocurrió con motivo de una misión que hizo al pueblo de Minas de Luz (hoy Progreso) en Cohauila el 22 de enero de 1889, en compañía de los Padres Vicente Luis Manci y Estinaslao Mauleón. Al apearse en Silao, se encontraron con el gobernador del estado, el general don Manuel González, que estaba frente al hotel San Julián. Tras tomar el parecer de sus compañeros, el Padre Antonio se decidió a acercarse y presentarle sus respetos. Según el Gerard Decorme, el P. Labrador se acercó al general y «le dijo que se alegraba de saludar a la primera autoridad del Estado» y que «aprovechaba aquella coyuntura para ponerse a sus órdenes; que, aunque en la República estaban las dos autoridades separadas, el Estado y la Iglesia, él [padre Antonio] acostumbraba, donde podía, visitar al que ejerciese la civil, porque siempre las misiones pretenden quitar peso de los gobernantes, morigerando los pueblos» ${ }^{40}$. No queriendo aceptar el asiento que le ofrecían, se limitó a decirle que tan sólo quería saludarlo y ponerse a sus órdenes, porque siempre las misiones pretenden quitar peso a los gobernantes.

$\mathrm{Al}$ despedirse, el general -que había perdido su mano derecha de una herida de bala en la batalla de Puebla- le alcanzó su mano izquierda. Entonces el Padre Antonio le dijo:

- Bizarro general, que en tantos combates ha mostrado su valor y por eso ha perdido un brazo. Dios le bendiga ${ }^{41}$.

El Presidente González había perdido el brazo derecho durante la batalla de Puebla de 1867, a causa de un balazo. Lo que había sido un hecho fortuito se convirtió pronto en motivo de censura y motivó la acusación de escritores

39 Félix SARdá y Salvany, El liberalismo, Imprenta del Círculo católico, México D. F., 1887, p. 209.

40 Gerardo DeCORME, Historia de la Compañía, pp. 93-94.

41 Ibid., p. 94. 
como Salvador Quevedo y Zubieta (1859-1935), un intelectual afín a Porfirio Díaz. En su campaña de descrédito, Quevedo aducía que a raíz de perder su brazo derecho, el presidente había desarrollado un gran apetito sexual, y que había mandado traer de Circasia a una mujer que se hospedaba en su hacienda de Chapingo ${ }^{42}$.

Irritado quizás por el insulto del P. Labrador, Manuel González envió a una serie de espías a Mineral de la Luz para que le mantuvieran informado sobre cualquier ofensa que pudiera cometerse. El P. Decorme hace una relación completa del enfrentamiento que tuvo lugar dentro de la iglesia y durante el cual el P. Labrador abofeteó al jefe político Carlos Beascoechea, lo que provocó un motín popular que se saldó con varios muertos ${ }^{43}$. El suceso concluyó con el arresto el P. Labrador en compañía de los PP. Manci (que había sido encarcelado como extranjero pernicioso en 1873) ${ }^{44}$ y Mauleón, y su posterior confinamiento en la cárcel de Granaditas, donde permanecieron desde el 25 de mayo de 1889 al 28 de marzo de $1890^{45}$. Según la sentencia dictada contra el P. Labrador el 31 de agosto del mismo año, la causa del arresto fueron «los delitos de infracción de las leyes de Reforma y motín ${ }^{46}$.

El 12 de agosto de 1889 el P. Labrador escribía a su hermana Francisca y prometía comunicarle el desenlace de «la cosa ruidosa y llena de odiosidad contra Dios y su santa religión que nos han formado» ${ }^{47}$. El 16 de octubre de 1889, el P. Labrador se dirigía al P. Donadoni, rector de la iglesia de los Servitas de Orizaba, dándole cuenta de la lentitud con la que se desarrollaba el proceso y felicitándose de la oportunidad que la estancia en la cárcel le daba para ejercer su apostolado:

Por acá con mi prisión estoy dando la gran Misión; y parece que no, mas veo que Vd. me ayuda con ese furor de protestantismo. ¡Vaya! que tiene bemoles el nuevo protestantismo!!

42 V. Salvador Quevedo y ZubIETA, Manuel González y su gobierno en México, Establecimiento Tipográfico en Montealegre, México D. F., 1885, p. 181.

43 Gerardo DECORME, Historia de la Compañía, pp. 93-108.

44 ALJ, vol. 7, México D. F., 1890, p. 238.

45 Para una relación detallada del proceso, v. Gerardo DeCORME, Historia de la Compañia, pp. 95 108. Véase también la obra de José GuTiÉRrez CASILlas, Fesuitas en México, pp. 276-301.

46 El pliego de cargos se refiere específicamente al artículo 1 de la ley de 30 de agosto de 1862 y la fracción III del art. 3 de la ley de 6 de diciembre de 1856 además del capítulo 11 de la del de adiciones y reformas del 14 de diciembre de 1874, además de varias disposiciones del título VI, cap. VIII, lib. 3 del Código Penal. ALJ, vol. 7, Imprenta del Sagrado Corazón de Jesús, México D. F., 1890 , p. 229.

47 Carta de Antonio Labrador a Francisca Labrador, 12 agosto 1889, AECJ, leg. 1471. 
En la misma carta, el P. Labrador daba cuenta de una hoja, impresa en León, y de una remesa de libros que por su contenido debían corresponder al opúsculo Espada espiritual ó la devoción del Santísimo Rosario (1892). En una posdata al pie de la misma carta, el P. Manci se refería a la lentitud del proceso y mencionaba menciona la mediación de la Sra. Antonia del $\mathrm{Moral}^{48}$, persona de grandes recursos y a quien los PP. se había dirigido por mediación de un tal Sr. Rosado ${ }^{49}$.

El 12 de setiembre firmaba el P. Labrador un pliego de descargo, donde explicaba que su misión en Mineral de la Luz fue proponer como modelo a Jesucristo, que el matrimonio civil no es válido entre católicos, que cuando habló de liberalismo se limitó a exponer la doctrina oficial de la Iglesia; que no fue su intención causar alarma entre los presentes; que los tres testigos que se nombraron estaban llenos de prejuicio; y salía al caso del hecho de que el P. Manci había sido declarado extranjero pernicioso en 1873. Finalmente, de sí mismo, declaraba:

También en cuanto a mi conducta, dice la sentencia, como sospechando, que no se sabe cuál sería antes del corto tiempo que permanezco por acá, aunque de mi bondad abonasen personas competentes. Me parece prudente decir que pueden pedir informes a donde quiera, ya en España donde viví hasta los 48 años, ya en la República, en la cual resido hace cuatro años. He sido hombre bien conocido, no sólo de jovencillo estudiando en Badajoz y Sevilla, sino desde los veinte años consagrado a DIOS, ya estudiando, ya enseñado, ya en los ministerios sagrados, en los cuales me empleo hace veinticuatro (...) Confieso, y esto es verdad, que soy de genio y enérgico; doy gracias a DIOS de esta nueva bonanza suya, porque, sin esa entereza, principalmente para el ministerio apostólico, nadie es a propósito, pues se requiere todo un acertado complejo de fogosidad y de firmeza, y de constancia, que no todos tienen, mayormente en estos tiempos, en que tanto domina el respeto humano, del cual nace, no pocas veces, la timidez y la cobardía. Pero ¿cuál es mi objeto? Desinteresadamente, ya lo he dicho, la gloria de DIOS y el bien ${ }^{50}$.

48 Antonia del Moral y Otero fue la segunda esposa de Gregorio Jiménez, quien falleció en 1883 y de quien heredó su fortuna. Intervino en la construcción del Colegio Jesuita de San Francisco Javier, que se completó en 1915. Amor MILDRED ESCALANTE, Entre redes y telarañas. Empresariado y vínculos familiares en la ciudad de Guanajuato, 1850-1911, Tesis Doctoral, Universidad San Luis, 2009, p. 45.

49 Carta de Antonio Labrador a Antonio Donadoni, 17 de octubre 1889, AECJ, leg. 1471. El P. Labrador no dudó en recurrir a las clases altas poblanas como doña Eduviges Hernández para sufragar algunas de sus iniciativas Eduviges Hernández figura como subscriptora de una carta protestando por la expulsión del obispo de México el 3 de octubre de 1957, A Collection of Pamphlets, chiefly political, vol. 8, Guadalajara, 1856, p. 6.

50 Protesta del Padre Antonio Labrador y Ruiz, en La voz de México, 20 de septiembre 1889, p. 2. 
Un año más tarde, en 1890, aparecía en Valladolid su opúsculo titulado: Ecos de un cautivo en Granaditas. Desagravios por las blasfemias de estos días, escritos por el M. R. Padre Misionero apostólico Antonio Labrador y Ruiz (1890). Lejos de hacer un recuento de su experiencia en la cárcel de Granaditas, el P. Antonio Labrador escribió una réplica contra dos opúsculos que le había hecho llegar a su prisión: Contra los sacerdotes y el Santísimo Sacramento de nuestros altares. Desde una perspectiva catequética, y orientada a la pastoral, el P. Antonio Labrador daba cuenta de la teología del sacerdocio y del Santísimo Sacramento, y aprovechaba para introducir una serie de invocaciones y de oraciones «al nuevo protector de la Iglesia San José» ${ }^{51}$, siguiendo con ello las directrices que Pío IX había dictado con ocasión del Concilio Vaticano $\mathrm{I}^{52}$.

\section{EL APOSTOLADO DE ORIZABA}

Las leyes de Reforma comenzaron su aplicación en Orizaba a partir de 1860, de manera tardía debido a que la ciudad permaneció por algún tiempo en mano de los conservadores. Para 1868, las autoridades constitucionalistas expulsaban a los religiosos de San José de Gracia, los de la Tercera orden de San Francisco, los Servitas, San juan de Dios y la Concordia ${ }^{53}$.

Para finales de 1889, el P. Labrador se hallaba viviendo ya en la casa de la Compañía en Orizaba en compañía de los PP. Donadoni y Mauleón. El asentamiento de los jesuitas en Orizaba remontaba al año 1867, cuando el obispo Suárez invitó a los jesuitas a que abrieran una casa en 1867 con el fin de incrementar el número de religiosos en la ciudad ${ }^{54}$. En poco tiempo, el P. Labrador llevó a cabo doce misiones entre Orizaba y Misantla, con gran éxito. Sin embargo, el celo de los sacerdotes no pudo suplir las deficiencias de un clero que se mostraba

51 Antonio Labrador, Ecos de un cautivo en Granaditas, Imp. y Librería de la Viuda de Cuesta, Valladolid, 1890, p. 11.

52 El 8 de diciembre de 1870, en el Concilio Vaticano, interrumpido por los acontecimientos políticos, aprovechó la feliz coincidencia de la fiesta de la Inmaculada para proclamar más solemne y oficialmente a San José como Patrono de la Iglesia universal y elevar la fiesta del 19 de marzo a rito doble de primera clase (Decr. Quemadmodum Deus, 8 de diciembre de 1870; Acta Pii IX, P. M., vol. 5, Roma 1873, p. 282.).

53 José María NAREDO, Estudio geográfico: histórico y estadístico del cantón y de la ciudad de Orizaba, Imprenta del Hospicio, Orizaba, 1898, p. 156.

54 John Baker Williman, Church and State in Veracruz, 1840-1940: the concord and conflicts of a century. PhD Dissertation, U of Saint Louis (Missouri), 1972, p. 36. 
incapaz de seguir su labor y de unos fieles que a menudo no comprendían el alcance de sus confesiones ${ }^{55}$.

Para cuando el P. Labrador llegó a Orizaba, había cuatro comunidades de religiosos, pero se echaba en falta una casa de ejercicios. En los primeros años, afirma Guerrero, los Padres jesuitas se limitaban a las antiguas labores de apostolado y a las funciones ordinarias de la iglesia. El P. Labrador supo «dar un cariz más apostólico a los ministerios a través de numerosas tandas de ejercicios e incansable dedicación por toda la ciudad y sus contornos ${ }^{56}$. Además de construir una casa de ejercicios, el P. Labrador fue responsable en 1904 de la construcción de una casa de ejercicios ${ }^{57}$. En 1911 se llevaba a cabo la fundación del hogar Santa Isabel para ancianos desamparados, contando, eso sí, con ayuda de la Sra. Elena Vivanco Amor, propietaria de la hacienda El fazmín y propietaria de la fábrica de cerveza Santa Elena $(1838-¿ \text { ? })^{58}$.

El tono de estos años viene dado por otro sermón que el P. Labrador pronunció en Orizaba posiblemente en agosto de 1889 en conmemoración de «los santos y beatos nuevamente elevados a los altares por su Santidad León XIII en estos últimos años, 1886-1888)». La canonización múltiple que dio pie al sermón se produjo el 15 de enero de 1588 e incluyó a los beatos Pedro Claver, Edmundo Capiano y compañeros mártires, S. Alonso Rodríguez, coadjutor temporal de la compañía de Jesús, los siete santos fundadores de la orden de los siervos de la Virgen y Juan Berchmans.

A la hora de componer el sermón de Orizaba, el P. Labrador se inspiró con toda probabilidad en una Vida de San Alonso Rodríguez (1888), publicada por P. Jaime Nonell S. J. (1824-1922) en $1888^{59}$. Concebida como apología contra el protestantismo ${ }^{60}$, la obra de Nonell encomiaba el ejemplo de San Alonso Rodríguez y San Pedro Claver para animar a sus feligreses a que los imitaran y salía así al paso de la amenaza liberal. En el mismo sentido se declaraba el P. Labrador cuando escribía: «imitemos nosotros sus virtudes, siendo fieles a la gracia y celosos, hasta la heroicidad, con los prójimos, haciéndoles cuanto bien poda-

55 John Baker Williman, Church and State, p. 71.

56 José GuTiérRez CasiLlas, Fesuitas en México, p. 50.

57 Carta de Antonio Labrador a Tomás Ipiña, 2 de diciembre 1904. CEC, vol. 5, pp. 166-167.

58 DGRM, tomo 1, 1903-1904, Orizaba, Ruhland \& Ahlschier, 1903, p. 645.

59 Jaime Nonell, Vida de San Alonso Rodríguez: coadjutor temporal de la Compañía de fesús, Impr. y Librería de J. Subirana, Barcelona, 1888, p. 639.

60 Patrick J. HAYES, Fesuit Saint Making: The Case of St. Peter Claver's Cause in Nineteenth-Century America, en American Catholic Studies, 17/4 (2006), p. 1. 
mos, según el estado en que nos colocó el Señor» ${ }^{61}$.

En general, el tono del sermón de Orizaba señalaba el paso de una sensibilidad que iba de las postrimerías a las promesas de la vida ejemplar. Poniendo mayor énfasis en la salvación del hombre, los santos canonizados contribuían a ensalzar un deseo de salvación espiritual y propiciaban su intervención salvífica. En este sentido, el sermón de Orizaba evidenciaba un cambio del sermón apostólico y un interés por desarrollar un estilo homilético que se acercaba al sermón pastoral. En su interés por aportar ejemplos directos a sus feligreses, el P. Labrador no dudó en servirse de ejemplos cercanos y de invocar tampoco el poder de la literatura y de las imágenes. Fruto de estos años son un tratado sobre La Virgen Purísima Nuestra Señora de Guadalupe y la nación mexicana $(1892)^{62}$, Espada espiritual ó la devoción del Santísimo Rosario

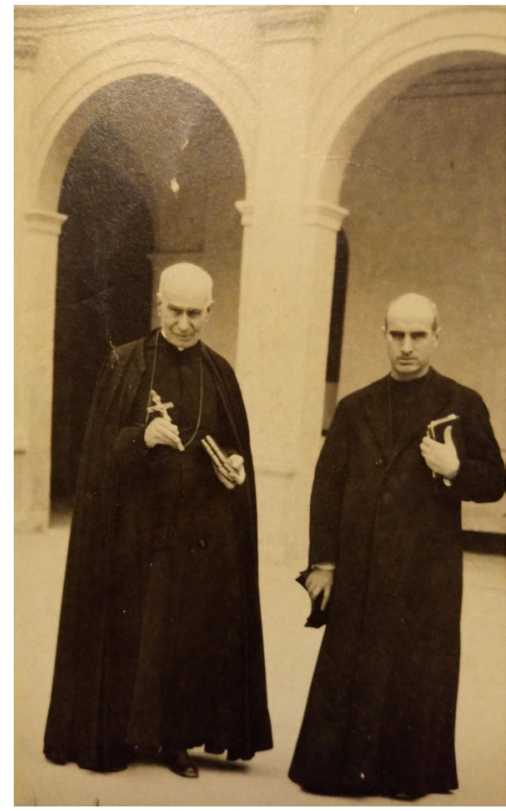

El P. Antonio con en P. Ignacio Velasco (18341891), obispo de Bogotá, en la iglesia del Carmen de Orizaba (México), c. 1889 (col. del autor). $(1892)^{63}$; Las cosas pequeñas en el ejercicio de la virtud perfecta $(1892)^{64}$, Vida de San Juan de Dios y devoción para el día 8 de cada mes $(1897)^{65}$, Novena a la Virgen purísima de Guadalupe (1897) ${ }^{66}$, y Devoción en honor de San Antonio de Padua $(1899)^{67}$.

61 Antonio Labrador, Sermón de San Pedro Claver, Orizaba, ¿1989?, s. n., AECJ, leg. 1471.

62 Antonio Labrador, La Virgen Purísima Nuestra Señora de Guadalupe y la nación mexicana, Benziger \& Co., Ensiedeln (Suiza), 1892.

63 Antonio LABRADOR, Espada espiritual ó la devoción del Santísimo Rosario, Benziger \& Co., Ensiede$\ln$ (Suiza), 1892.

64 Antonio LABRADOR, Las cosas pequeñas en el ejercicio de la virtud perfecta, Benziger \& Co., Ensiedeln (Suiza), 1892.

65 Antonio Labrador, Vida de San fuan de Dios y devoción para el día 8 de cada mes, Imprenta del Sagrado Corazón, México D. F., 1897.

66 Antonio LABRADOR, Novena a la Virgen purísima de Guadalupe, Herros Editores, México D. F., 1897.

67 Antonio Labrador, Devoción en honor de San Antonio de Padua, Tipografía y Litografía Salesianas, Puebla, 1899. 


\section{LA VIRGEN DE GUADALUPE}

Las leyes de reforma intentaron sin gran éxito suprimir el culto de la Virgen de Guadalupe ${ }^{68}$. La coronación de la Virgen en 1885 supuso un triunfo para la causa conservadora, que veía en la exaltación de la Virgen un argumento en contra de la campaña anticlerical de ciertos sectores ${ }^{69}$. En un intento por apartarse de las acusaciones de mariolatría ${ }^{70}$, los jesuitas fomentaron el culto de la Virgen de Guadalupe como símbolo de la «Fe verdadera y cristiana». Según Bravo Ugarte, la controversia en torno a la autenticidad de las apariciones se resolvió en una carta que el Obispo dirigió al Papa León XIII en representación de todos los obispos de México y donde agradecía el oficio de la Virgen de Guadalupe, pero puso también en evidencia la importancia que la Virgen tenía a la hora de contrarrestar los efectos de la enseñanza oficial ${ }^{71}$.

En mayo de 1909, el P. Antonio Labrador fue invitado a predicar doce sermones en el santuario de la Virgen de Guadalupe. El primer sermón se inicia con un pasaje del Génesis que aparece también sobre la puerta principal de templos como el de la catedral de Coyoacán y en la iglesia de los dominicos de Porta Coeli (México): «Non est his aliud nisi Domus Dei et Porta Coeli» (Gen. 28, 16-17). Dentro de las Meditaciones para uso de los eclesiásticos publicadas en Morelia en 1859, el verso del Génesis figura como un recuerdo de que «nuestras iglesias están llenas de la Majestad divina, que Dios está tan presente allí como en el cielo» e invita a tomar la resolución de «reanimar nuestra fé al entrar en ellas, acordándonos de que este lugar es terrible, y que no debemos presentarnos allí sino con un religioso terror» ${ }^{72}$. El resto de los sermones sigue en parte el Sermo S. Hieronymi Presbyteri (lectio IV) correspondiente al día de la Inmaculada Concepción (8 de diciembre), donde se trata precisamente de la Virgen María ${ }^{73}$. El P. Labrador añade luego pasajes del acervo popular para ilustrar la explicación del texto sagrado. Escritos en el ambiente de inestabilidad política que dominó el principio de la revolución, los sermones del P. Labrador

68 Francisco Bulnes, fuárez y las revoluciones de Ayutla y de reforma, México D. F., 1905, p. 351.

69 Regis Planchet, La cuestión religiosa en México, Imprenta moderna, México D. F., 1956, p. 486. Cit. José Bravo UGarte, Catolicismo y porfiriato, en Historia de México, 7/3 (1958), p. 438.

70 José Bravo Ugarte Catolicismo, p. 438.

71 Francisco Banegas Galván, Cuestiones Mexicanas, Béjar, 1915, inédito. Cit. José Bravo UGaRTE, Catolicismo, p. 441.

72 Meditaciones para uso de los eclesiásticos, Impr. de Andrade y Escalante, México D. F., 1859, p. 78.

73 BR, p. 485. 
insistían sobre el papel que la devoción a la Virgen había ocupado en la vida de los mexicanos, por encima de los avatares políticos y las guerras que se habían sucedido en los últimos trescientos años ${ }^{74}$.

\section{REGRESO A ESPAÑA}

Para los jesuitas de México, la revolución mexicana inició un período de dificultades que se acentuó con la expulsión decretada en 1914 por Venustiano Carranza. El 26 de diciembre de 1909 escribía el P. Labrador a s sobrina y le decía: «no veo la posibilidad de volver a España; mis superiores de Roma me mandaron el 1885 para ayudar a los padres de esta nación; el gusto de ellos es que permanezca; de modo que la voluntad de Dios es bien conocida de que por acá trabaje en beneficio de la Sta. Iglesia y la Compañía. ¿Qué hacer, sino sostener el banco, mientras hay fuerzas?» Y más adelante: «Quién se atreve a estar allá, con tanta guerra como se hace a la religión, en España... Por acá, silencio. Si alguien se desmanda, le quitan del medio; porque hay un gobierno fuerte, el cual no se anda en contemplaciones $>^{75}$.

El período de estancia en el Puerto de Santa María coincidió con la publicación de un librito que el P. Labrador pretendía distribuir con motivo de sus bodas sacerdotales de oro el 15 de agosto de 1915. El 30 de julio de 1915 escribía a su sobrina Rosario y le pedía que imprimiera un opúsculo para repartir en la misa ${ }^{76}$. Dos días más le volvía a escribir al su sobrina Rosario para anunciarle el envío de mil quinientos ejemplares del devocionario del P. Vilariño, y le encargaba que repartiese a varias personas de Zufre: «cien al cura; cien a su sobrino Manuel Hidalgo; cien a Saturnino Herrera; cien a don Mendizábal, cien a D. Vicente

74 «Sermones de la basílica de Nuestra Señora de Guadalupe en Mayo de 1909», s.p. AECJ, leg. 1471. Según carta del 21 de mayo de 1909, el sermón del P. Labrador coincidió con la llegada de un sobrino, Ceferino Labrador, quien tuvo oportunidad de asistir con él a la iglesia de Guadalupe. Ceferino Labrador era hijo de su hermana María y había hecho la travesía a México con la esperanza de encontrar algún trabajo. La falta de aptitud y de disposición de Ceferino se vio agravada por la situación política por la que atravesaba el país. Preocupado por Ceferino, el P. Labrador le comunicaba a su sobrina en 1909 la necesidad de enviar algún dinero y decía «también aquí tenemos que atenernos a vivir con mucho cuidado, y reservarnos, porque a lo mejor se desata una revolución, y entonces es necesario contar con lo presente». «Carta a Rosario Labrador», 21 de junio 1909, AECJ, leg. 1471.

75 «Carta a Rosario Labrador», 26 diciembre 1909, AECJ, leg. 1471.

76 Ecce Sacerdos Magnos, dedicado al Padre Antonio Labrador, Jaén, Tipografía La Unión, 1915, p. 6. 
Quevedo...»77. En el opúsculo, el padre Saturnino Hernández, canónigo de la catedral de Jaén, explicaba la labor del jesuita y concluía diciendo:

Publicado en 1900, el devocionario del P. Vilariño se hallaba ligado al Apostolado de la oración y promovía una espiritualidad regida por una distinción entre «los que acudían a la religión para buscar protección, los que realmente se proponían honrar a Cristo y los que siguiendo el espíritu original de la consagración parediana, se comprometían además a llevar una vida cristiana más perfecta, en la que el amor a Cristo y el espíritu de reparación constituían elementos importantes ${ }^{78}$. El devocionario de Vilariño se asociaba íntimamente con la figura del Sagrado Corazón y en él se proponían algunas orientaciones prácticas para llevar a cabo la vida religiosa y que habría de servir como «primera piedra sobre la que se edifique el edificio de la conversión o santificación de la familia» ${ }^{79}$.

El P. Labrador falleció el 5 de agosto de 1915 en el colegio, a los 79 años de edad. En su necrológica, el P. Ipiña reconoce que se le reconocían una curación de enfermedad (un hombre sanó dándosele a besar una estampa) ${ }^{80}$, profecías verificadas, una bilocación: «Meses antes de que estallara la revolución que derribó al Presidente, general Díaz, madre de la anarquía que aún dura en Méjico, le oí decir más de una vez que trabajos y castigos iban a caer sobre aquella República» ${ }^{81}$.

De un modo u otro, la labor evangélica del P. Labrador se caracterizó por la transición de un espíritu apostólico a un estilo apologético que veía en la religión un refugio contra la inestabilidad política de España y México en los últimos años del siglo XIX. Fiel seguidor de la obra de autores como Félix Sardá y Remigio Vilariño, el P. Labrador optó por devolver un papel destacado a la oración y establecer un modelo de vida que convirtiera a los cristianos en verdaderos apóstoles de su fe. En este sentido, la injusticia de la que fue objeto con ocasión de la misión de

77 Remigio VILARIÑO, Devocionario completo, El Mensajero del Corazón de Jesús, Bilbao, ¿1900?

78 Luis CANO MEdina, Reinaré en España: La mentalidad católica a la llegada de la Segunda República, Encuentros, Madrid, 2009, p. 96.

79 Remigio VILARIÑo, La consagración de las familias al corazón de fesús, en El Mensajero del Corazón de fesús (1919), p. 413.

80 La estampa en cuestión fue sufragada por Salvador Diez de Bonilla y Valenzuela, abogado de México D.F. (1870-¿?).

81 Cartas edificantes de la provincial de Toledo, vol. 3, Madrid, 1914, p. 279. El 25 de octubre de 1909 escribía una vez más a su sobrina Rosario: «cuánto deseo que las hijas de las Américas amen a la Madre Patria, ahora tan decrépita, por las mefíticas semillas sembradas en sus campos!!! Mi madre lloraba el 1854 en el Pronunciamiento de junio!!!» Carta a Rosario Labrador, 25 de octubre 1909, AECJ, leg. 1471. 
Mineral de la Luz y la prisión en la cárcel de Granaditas no hicieron sino reforzar sus convicciones y lo animaron a publicar una serie de opúsculos y libros con los que completar una definición católica de la nación que sirviera de bastión frente a la impiedad y la descristianización.

\section{SIGLAS}

AECJ Archivo Español de la Compañía de fesús.

ALJ Anuario de legislación y jurisprudencia: Sección de jurisprudencia.

BR Breviarium Romanum. Pars Hiemalis, Cincinatti, 1886.

CEC Cartas edificantes y curiosas de la Asistencia de España, Sociedad Bilbaína de Artes Gráficas, Bilbao, 1906.

CEPT Cartas edificantes de la provincia de Toledo de la Compañía de fesús.

CP Cartas de Poyanne.

DGRM Directorio general de la República Mexicana.

\section{REFERENCIAS BIBLIOGRÁFICAS}

Banegas galván, Francisco, Cuestiones Mexicanas, Béjar, 1915.

BASTIAN, Jean Pierre, Protestantes, liberales y francmasones: Sociedades de ideas y modernidad en América Latina, siglo XIX, Fondo de Cultura Económica, México, 1990.

Bravo Ugarte, José, Catolicismo y porfiriato, en Historia de México, 7/3 (1958), pp. 437-441.

BULNES, Francisco, Fuárez y las revoluciones de Ayutla y de reforma, México, 1905, p. 351.

CANO MEdina, Luis, Reinaré en España: La mentalidad católica a la llegada de la Segunda República, Encuentros, Madrid, 2009.

CARCEL ORTI, Vicente, Iglesia y revolución en España, EUNSA, Pamplona, 1979.

Cárdenas Ayala, Elisa, El fin de una era: Pío IX y el Syllabus, en Historia Mexicana, 65/2 (2015), pp. 719-746.

CheNILLO AlaZRAKI, Paola, Liberalismo a prueba. La expulsión de los extranjeros perniciosos en México durante la república restaurada (1867-1876), en Revista de Indias, 72/255 (2012), pp. 377-408.

DeCORME, Gerard, Historia de la Compañía de fesús en la República mexicana, Ediciones Canisio, Chichuahua, 1959.

Ecce Sacerdos Magnos, dedicado al Padre Antonio Labrador, Tipografía La Unión, Jaén, 1915.

MiLDRED ESCALANTE, Amor, Entre redes y telarañas. Empresariado y vinculos familiares en la ciudad de Guanajuato, 1850-1911, Tesis Doctoral, Universidad San Luis, 2009.

FOULARD, Camile, Hacia los límites del cuerpo: Prácticas penitenciales de una mística católica en la Revolución Mexicana, en Trace, 72 (2017), pp. 9-33.

FRíAs, Lesmes, La provincia de Castilla de la Compañia de Fesús desde 1863 hasta 1914: reseña histórica, El Mensajero del Corazón de fesús, Bilbao-Deusto, 1915. 


\section{ADRIANO DUQUE}

Gómez NaVArro, María Soledad, Con la palabra y los gestos. Las misiones populares como instrumento de cristianización y recristianización en la España Moderna, en Ámbitos, 19 (2008), pp. 11-23.

Gutiérrez Casillas, José, Fesuitas en México durante el siglo XIX, Porrúa, México, 1972.

HaYes, Patrick J. Jesuit Saint Making: The Case of St. Peter Claver's Cause in Nineteenth-Century America, en American Catholic Studies, 17/4 (2006), pp. 1-32.

HERnáNDEZ y Dávalos, J. E., Colección de documentos para la historia de la Guerra de Independencia de México, vol. 4, J. M. Sandoval, México, 1878.

HERZOG, Félix, La crisis de los principios espirituales y sociales del proceso penal reformado, en Ius et Praxis, 15/1 (2009), pp. 375-386.

HibBS-LiSSORGUES, Solange, El liberalismo es pecado. Estudio preliminar y edición, Pagès Editors, Lérida, 2009.

Labrador, Antonio, Protesta del Padre Antonio Labrador y Ruiz, en La voz de México, 20 de septiembre 1889.

- Ecos de un cautivo en Granaditas, Imp. y Librería de la Viuda de Cuesta, Valladolid, 1890.

- La Virgen Purísima Nuestra Señora de Guadalupe y la nación mexicana, Benziger \& Co., Ensiedeln (Suiza), 1892.

- Espada espiritual ó la devoción del Santísimo Rosario, Benziger \& Co., Ensiedeln (Suiza), 1892.

- Las cosas pequeñas en el ejercicio de la virtud perfecta, Benziger \& Co., Ensiedeln (Suiza), 1892.

- Vida de San Juan de Dios y devoción para el día 8 de cada mes, Imprenta del Sagrado Corazón, México, 1897.

- Novena a la Virgen purísima de Guadalupe, Herros Editores, México, 1897.

- Devoción en honor de San Antonio de Padua, Tipografía y Litografía Salesianas, Puebla, 1899.

Meditaciones para uso de los eclesiásticos, Impr. de Andrade y Escalante, México, 1859.

Mendirichaga Dalzell, José Roberto, El colegio de San Fuan Nepomuceno, 1878-1914: presencia de los Fesuitas desde Saltillo, Tesis doctoral, Universidad Iberoamericana, México, 2007.

MENESES, Ernesto, Tendencias educativas oficiales en México, 1821-1911, Centro de Estudios Educativos y Universidad Iberoamericana, México, 1998.

Moliner Prada, Antonio, Algunos aspectos del anticlericalismo español en la revolución de 1868 , en Investigaciones históricas. Época Moderna y contemporánea, 14 (1994), pp. 137-158.

MunTaDas ANDRADE, José, Memoria que sobre el Instituto de Badajoz durante el curso de 1959 á 60, leyó en la solemne apertura del curso, el 16 de septiembre de 1860, el Sr. director del mismo Don Fosé Muntada y Andrade, Imp. y Lib. de D. G. Orduña, Badajoz, 1859.

O'MALlEy, John, Saints or Devils Incarnate? Studies in Fesuit History, Brill, Leiden, 2013.

NAREDO, José María, Estudio geográfico: bistórico y estadístico del cantón y de la ciudad de Orizaba, Imprenta del Hospicio, Orizaba, 1898.

Nonell, Jaime, Vida de San Alonso Rodríguez: coadjutor temporal de la Compañía de Jesús, Impr. y Librería de J. Subirana, Barcelona, 1888.

PALOMERA, Esteban, La obra educativa de los jesuitas en Guadalajara, 1586-1986, Instituto de Ciencias, México, 1997.

PlanCHET, Regis, La cuestión religiosa en México. Imprenta moderna, México, 1956.

Quevedo y ZubIETA, Salvador, Manuel González y su gobierno en México, Establecimiento Tipográfico en Montealegre, México, 1885. 
REVUELTA, Manuel, Estabilidad y progreso de la Compañía durante la restauración alfonsina (18751931), en Los jesuitas en España y en el mundo hispánico, ed. Teófanes Egido, Marcial Pons, Madrid, 2004.

- La Compañia de fesús en la España contemporánea: Supresión y reinstalación, vol. 1, Sal Terrae, Madrid, 1984.

- La Compañía de Jesús en la España Contemporánea: Palabras y Fermentos, vol. 3, Sal Terrae, Madrid, 1984.

- Las misiones de los jesuitas españoles en América y Filipinas durante el siglo XIX, en Miscelánea Comillas, 46/88-89 (1998), pp. 339-390.

SÁNCHEZ PASCUAL, Felicidad, El instituto de segunda enseñanza de Badajoz en el siglo XIX (18451900), Excma. Diputación, Badajoz, 1985.

SARDÁ Y SALVANY, Félix, El liberalismo, Imprenta del Círculo católico, Madrid, 1887.

VILARIÑO, Remigio, Devocionario completo, Bilbao, El Mensajero del Corazón de Jesús, ¿1900?

- La consagración de las familias al corazón de fesús, en El Mensajero del Corazón de fesús (1919), pp. $400-421$.

WILliman, John Baker, Church and State in Veracruz, 1840-1940: the concord and conflicts of a century. PhD Dissertation, U of Saint Louis (Missouri), 1972.

YTURBE, Corina, Las Leyes de Reforma: ¿Laicidad sin secularización?, en Isonomía, 22 (2010), pp. 65-81.

ZERMEÑO PADILLA, Guillermo, El retorno de los jesuitas a México en el siglo XIX: algunas paradojas, en El Colegio de México, 64/4 (2015), p. 1524. 
0000 